\title{
Partnering and parenting transitions associate with changing smoking status: a prospective cohort study in young Australians
}

\author{
Jing $\operatorname{Tian}^{1}$, Seana Gall ${ }^{1}$, George Patton ${ }^{2}$, Terry Dwyer ${ }^{1,3}$, Alison Venn ${ }^{1 *}$
}

Concise title: Associations of partnering and parenting transitions with changing smoking status in young adults

${ }^{1}$ Menzies Institute for Medical Research, University of Tasmania, Hobart, Tasmania, Australia

${ }^{2}$ Murdoch Childrens Research Institute, Melbourne, Victoria, Australia

${ }^{3}$ The George Institute for Global Health, University of Oxford, Wellington Square, Oxford, United Kingdom

1 Corresponding author:

Alison Venn *, Menzies Institute for Medical Research, University of Tasmania, 17 Liverpool

3 Street, Hobart, Tasmania, 7000, Australia; Phone: +61 36226 7706; Fax: +61 36226 7704;

4 Email: Alison.Venn@utas.edu.au

Funding: This study was supported by grants from the National Health and Medical Research Council (NHMRC 211316 and 544923), the National Heart Foundation (GOOH0578), the Tasmanian Community Fund and Veolia Environmental Services. We gratefully acknowledge the study sponsors Sanitarium, ASICS and Target. Alison Venn was supported by a NHMRC Research Fellowship (APP1008299), Seana Gall was supported by a Heart Foundation Public Health Post-Doctoral Fellowship (PH 11H6047) and Future Leader Fellowship (100448).

Conflict of Interest: The authors declare that they have no competing interests. 


\section{Abstract}

2 Objectives To examine the effects of partnering and parenting transitions on smoking 3 continuity in young adults.

4 Methods A prospective cohort study involving 1,084 young smokers and former smokers

5 who completed questionnaires at baseline (2004-06, aged 26-36 years) and 5-year later.

6 Results 233/570 (40.9\%) smokers quit and 58/514 (11.3\%) former smokers resumed 7 smoking during follow-up. For partnering transitions, compared with remaining not 8 partnered, the likelihood of quitting was higher among men who became (RR: 2.84 95\% CI:

9 1.62, 4.98) or stayed (RR: 2.12, 95\% CI: 1.18, 3.80) partnered and women who became 10 partnered (RR: 1.50, 95\% CI: 1.03, 2.18). People who became (RR: 0.14, 95\% CI: 0.03, 0.58) 11 or stayed (RR: 0.51, 95\% CI: 0.27, 0.95) partnered had a lower risk of resuming smoking 12 than their continuously not partnered peers. For parenting transitions, having a first child born 13 increased women's probability of quitting smoking relative to remaining childless (RR: 1.74, 14 95\% CI: 1.30, 2.33), while having additional children did not.

15 Conclusions The benefits of partnering were greater for men than women, and transition into 16 parenthood was of greater benefit to women.

17 Keywords: marital status; parenthood; smoking cessation; longitudinal studies 
2 Young adults often make important life-stage transitions as they complete education or

3 training and enter work, and as their family, work, and financial responsibilities increase.

4 Two important life-stage transitions are becoming partnered and having children. Over recent

5 decades, transitions into marriage and parenthood have been occurring at later ages. In

6 western countries, such as Australia in 2013, the median age at first marriage was 29.9 years

7 for males and 28.3 for females (Australian Bureau of Statistics 2013) and the average age of

8 first time mothers was 28.6 (Australian Institute of Health and Welfare 2015). Life-stage

9 transitions are often viewed as a time of “maturing out” and accompanying major changes in social networks, social roles, responsibilities and expectations, which may impact physical and mental health positively or negatively (Raymore et al. 2001; Wheaton 1990).

Cigarette smoking is a common unhealthy behaviour. It is the leading preventable cause of death and illness worldwide, with about half of current smokers dying prematurely from a tobacco-related disease, including various cancers, cardiovascular disease, respiratory disease and other illness. In spite of a decreasing smoking prevalence in Australia (Australian Institute of Health and Welfare 2014), the risks of smoking remain high, with up to twothirds of deaths in current smokers attributed to smoking (Banks et al. 2015).

In Australia and other high income countries, young adulthood is a critical period when smoking prevalence peaks and when progression from experimental to regular smoking often occurs (Australian Institute of Health and Welfare 2014; U.S. Department of Health and Human Services 2012). It is also a time for establishing life-partnerships and having children. Providing an in-depth exploration of the effects of partnering and parenting transitions on smoking continuity, cessation and relapse in this critical time is important for health practitioners and policy makers to optimise and reinforce their work to promote quitting, 
1 discourage relapse and enhance sustained cessation; however, few longitudinal studies exist.

2 In a longitudinal study of young women from Australia (McDermott et al. 2009), marriage,

3 being in a committed relationship or being a mother significantly decreased the risk of

4 continuing and resuming smoking but this study included young women only. The effects in

5 young men are unclear. Two longitudinal studies prospectively examined the effects of

6 marital transitions on changes in health behaviours (Eng et al. 2005; Lee et al. 2005),

7 including cigarette smoking. However, participants of these two studies were middle-older

8 aged, and were primarily registered female nurses or male health professionals with similar

9 socioeconomic status so the results may not be generalisable to young adults and other

10 socioeconomic groups. A further limitation of previous studies is inadequate control for

11 confounding, with some potential confounders, such as social support and psychiatric diagnosis, which are imbalanced in different family structures (Shapiro and Keyes 2008) and causally associated with the maintenance and relapse of smoking (Diemert et al. 2013;

14 Mendel et al. 2012; Vangeli et al. 2011) not considered.

In the current study, we examined the associations between partnering and parenting transitions and smoking continuity, cessation and relapse in a population-based national

17 cohort of adults aged 26 to 36 years at baseline who were followed up 5 years later. We also wanted to investigate whether these effects differed between men and women. 


\section{Methods}

\section{Design and participants}

3 Participants were from the Childhood Determinants of Adult Health (CDAH) study (Gall et

4 al. 2009). It is a follow-up of 8,498 participants from the 1985 Australian Schools Health and

5 Fitness Survey (ASHFS), which comprised a nationally representative sample of Australian

6 school children aged 7-15 years. During 2002-2004, 6,840 participants were traced and

$7 \quad 5,170$ agreed to take part in the CDAH Study. The first follow-up was conducted from 2004 to 2006 (CDAH-1, herein referred to as 'baseline’) where 3,948 participants (aged 26-36

9 years) completed questionnaires and 2,410 of those attended one of 34 study clinics held around Australia for physical measurements. Five years later in 2009-2011, the second follow-up (CDAH-2, herein referred to as 'follow-up') collected data from 2,810 participants aged 31-41 years via telephone, mail or online survey. The study protocol was approved by the Southern Tasmanian Health and Medical Ethics Committee. Written informed consent was obtained from all participants included in the study at both time points.

The analyses for this study included participants who were current or former smokers at baseline, had data on smoking at follow-up, marital and parental status at both baseline and follow-up, socio-demographic factors and other covariates at baseline ( $\mathrm{n}=1,084$, Figure 1). Compared with current or former smokers who were not included in the analyses due to any aforementioned reason, those who did were more often females, had a higher body mass index (BMI) and education level, were more likely to be employed as professionals or managers, were more often married or living as married and had children at baseline. There was no statistically significant difference between the two groups in baseline age (data not shown). Using data from the initial childhood assessment, we also explored the extent to which the adult cohort represented the childhood sample. As shown in the Online Source 
1 not assessed $(n=4,550)$ as indicated by their greater prevalence of healthy weight, greater

2 height, and better performance in a range of fitness measures.

\section{Marital status and partnering transitions}

$4 \quad$ Participants reported their current marital status at baseline and follow-up. Marital status was

5 categorised into three groups: single, married/living as married, and

6 separated/divorced/widowed. Partnering transitions were classified as: not partnered

7 (married/living as married) both times, became partnered, stayed partnered both times, and

8 became separated/divorced/widowed. The group of not partnered both times was used as the

9 reference group in analyses. People who became separated/divorced/widowed were

10 compared to those who stayed partnered.

\section{Parental status and parenting transitions}

At follow-up, participants reported how many biological children they had and the month and year of birth for each child. The date the participant completed the baseline questionnaire was used to determine whether each child had been born before or after the baseline assessment. Participants were then classified into four groups: no children both times, had first child born since baseline, had additional children born since baseline, and same number of children both times. If a participant had their first child plus additional children since baseline, they were classified as having a first child born since baseline. The group of no children both times was used as the reference group in analyses.

\section{Smoking status assessment}

Smoking status was defined according to the responses to two questions at baseline and follow-up. The first question asked "Over your lifetime, have you smoked at least 100 cigarettes, or a similar amount of tobacco?” Participants answering “yes” were classified as ever smokers, and those answering "no" as never smokers. Ever smokers were then asked the second question "How often do you now smoke cigarettes, cigars, pipes or any other tobacco 
1 products?” Participants who answered "not at all” were classified as former smokers, those

2 who answered "daily” or "at least once a week" or "less than weekly" were classified as

3 current smokers.

$4 \quad$ Analyses were restricted to ever smokers at baseline as the main outcomes were quitting

5 and resuming smoking during follow-up. Current smokers were dichotomised as continuing

6 smokers and quitters. Former smokers were dichotomised into stable former smokers and

7 resumed smokers.

\section{Covariates}

9 Socio-demographic information was self-reported at baseline, including age, sex, education and occupation. Accessibility/Remoteness Index of Australia (ARIA) classifications (residing in major city vs other) were assigned to participants based on the census collection district of their residential address. BMI was calculated from measured weight and height for most participants. A 15-item Index for Social Support assessed participants’ perceptions and satisfaction with the social interaction available to them (Henderson et al. 1978). To control for poor health prior to beginning smoking, we used a question completed by participants in 1985 that asked “Is your health usually?” with responses of “very good”, “good”, “average”,

17 "poor" and "very poor". Current severe psychological distress was determined from the mental component summary measured by the 12-item Short Form Health Survey (Gill et al. 2007). Follow-up length was calculated from the dates the participant completed the baseline and follow-up questionnaires. Parenting transitions were considered as a covariate in the analyses of partnering transitions and vice versa.

\section{Statistical analyses}

23 Student t-tests and chi-square tests were used to compare differences in means and 24 proportions, respectively. The log binomial regression model was used to estimate the 
1 relative risk (RR) and 95\% confidence intervals of quitting or resuming smoking by

2 partnering and parenting transitions.

3 Covariates were considered as potential confounders if they were causally related to the

4 outcome, imbalanced between the exposure groups and caused a change of $10 \%$ or more in

5 the effect estimate when included in a given regression model. Interactions between sex and

6 partnering and parenting transitions on quitting or resuming smoking during follow-up were

7 measured in multivariable models. We separated men and women for the analyses of quitting

8 smoking because distinct sex differences were observed in the results $(\mathrm{p} \leq 0.10)$ (Aiken et al.

9 1991). The analyses of resuming smoking were not separated by sex as the p-values of

10 interaction terms were $>0.10$.

11 Sensitivity analyses were conducted using inverse probability weighting to examine the

12 effects of loss to follow-up on the results. Weights were determined by age, sex, education,

13 marital status and whether having children at CDAH-1 and also using complete childhood

14 variables specified in Table S1 (Online Source).

15 All analyses were performed with STATA software, version 12.1 (Stata Corp, College

16 Station, Texas 77845 USA). A two-tailed $P$ value less than 0.05 was considered statistically

17 significant. 


\section{Results}

2 In total, 1,084 ever smokers (570 current smokers and 514 former smokers) at baseline were

3 included in the analyses. Table 1 shows their baseline socio-demographic and anthropometric

4 characteristics. Overall, the mean age was 31.8 years, $40.4 \%$ were male, $27.8 \%$ were single

5 and 68.3\% were married or living as married; $46.1 \%$ did not have children. As compared with

6 former smokers at baseline, current smokers tended to be younger $(\mathrm{p}=0.013)$ and more often

7 male $(\mathrm{p}<0.001)$. They were less likely to have university education $(\mathrm{p}<0.001)$, to be

8 employed as professionals/managers ( $p=0.003)$, to be married/living as married $(p<0.001)$

9 and to have children $(\mathrm{p}<0.001)$. No significant difference was observed between the groups in baseline BMI.

During 5 years' follow-up, 233 (41\%) out of 570 current smokers at baseline quit smoking and 337 (59\%) continued; 58 (11\%) out of 514 former smokers at baseline resumed smoking and 456 (89\%) sustained cessation. The associations between the potential confounders and the partnering (Table S2) or parenting (Table S3) transitions are provided in Online Source.

The risk of quitting smoking relative to continuing smoking, and resuming smoking relative to remaining quit, from baseline to follow-up by partnering transitions is documented in Table 2 and Online Source Figure S1. Of all covariates examined, only age, education, parenting transitions and follow-up length were identified as confounders. There was an interaction between sex and partnering transitions in the analyses of quitting smoking $(p=0.078)$. For current smokers at baseline, after adjustment for covariates, the likelihood of quitting smoking was 184\% (95\% CI 62\%, 398\%) higher for men and 50\% (95\% CI 2\%, 118\%) higher for women who became partnered than those who were not partnered both times. A significant sex difference was observed in the effect of staying partnered on quitting smoking. Compared with those who were not partnered both times, men who stayed 
1 partnered reported a 112\% (95\% CI 18\%, 280\%) greater probability of quitting smoking,

2 while no significant difference was observed among women. Among former smokers at

3 baseline, relative to those who were not partnered both times, the risk of resuming smoking

$4 \quad$ was 86\% (95\% CI 97\%, 25\%) lower for those who became and stayed partnered.

5 Compared with those who stayed partnered, those who became

6 separated/divorced/widowed from baseline to follow-up showed lower risk of quitting

7 (males, RR 0.48 95\% CI 0.13, 1.69; females, RR 0.73 95\% CI 0.38, 1.38) and higher risk of

8 resuming smoking (RR 1.68 95\% CI 0.65, 4.38), but these differences did not reach statistical

9 significance.

Table 3 and Online Source Figure S2 presents the association of parenting transitions and continuity and relapse of smoking during follow-up. Of the covariates examined, only age, sex, education, partnering transitions and follow-up length were identified as confounders. An interaction was present between sex and parenting transitions in the analyses of quitting smoking ( $\mathrm{p}=0.072)$. Among female current smokers at baseline, compared with those who were childless both times, those who had a first child born since baseline were more likely to quit smoking in a multivariable model. Lower probabilities of quitting smoking were also evident when comparing with women who had additional children since baseline (RR 0.47, $95 \%$ CI $0.27,0.80)$ and women who had the same number of children at both time points (RR $0.4995 \%$ CI $0.33,0.72$ ) to those having their first child since baseline. There was no statistically significant difference in the likelihood of quitting smoking between people who had the same number of children both times and those who had additional children born since baseline. Among former smokers at baseline, no statistically significant difference was found between parenting transitions and whether resuming smoking from baseline to follow-up. 
1 Sensitivity analyses conducted using inverse probability weighting showed similar findings

2 as the unweighted analyses (Online Source Table S4 and S5). 


\section{Discussion}

2 We found becoming or staying partnered was significantly associated with an increased

3 probability of quitting smoking and a decreased risk of resuming smoking during 5 years'

4 follow-up. Associations were stronger among men than women. Marriage or partnership

5 termination was associated with higher risk of continuity and relapse of smoking, but these

6 associations were not statistically significant and should be interpreted with caution.

7 Regarding parenting transitions, we found compared with those staying childless, having a

8 first child was significantly associated with an increased likelihood of quitting smoking

9 among women, but not among men, whereas having additional children was not. To our knowledge, this is the first study examining the associations between partnering and parenting transitions and continuity or relapse of smoking by sex in young adults.

Our finding that becoming partnered, relative to remaining not partnered, was associated with a higher probability of quitting smoking and a lower risk of resuming smoking concurs with longitudinal studies among young women (McDermott et al. 2009; McDermott et al. 2004) and middle aged or elderly women (Lee et al. 2005). We observed greater benefits among young men. Men who stayed partnered were $112 \%$ more likely to quit smoking than their continuously not partnered peers. This is the first population-based study on the relationship between partnering transitions and smoking cessation reported by young men. As we hypothesised, the health benefits of marriage or partnership on quitting smoking differed between sex, with greater benefits among young men than women, which may be explained by different family roles of men and women. Women usually act as the primary family caregivers, and the social support husbands gain from their wives may be greater than vice versa (Umberson et al. 1996). Other possible explanations may include women’s greater encouragement of regulatory health behaviours and prevention practices benefiting their spouses.(Umberson 1987) The lower prevalence of smoking among young women than men 
1 may also be a reason. According to the latest report from the Australian Institute of Health

2 and Welfare, females were less likely to have smoked at any frequency than males

3 (Australian Institute of Health and Welfare 2014), and living with non-smoking partners

4 could significantly increase smokers' quitting attempts (Tucker et al. 2005) and success

5 (Manchon Walsh et al. 2007).

6 Compared to staying married or partnered, a shift from married or partnered to

7 separated/divorced/widowed was associated with increased, although not statistically

8 significantly, risks of continuity and relapse of smoking, which is consistent with previous

9 reports (Eng et al. 2005; Lee et al. 2005; Umberson 1992). In a cohort study of male health

10 professionals aged 40-75 (Eng et al. 2005) and a national panel survey (Umberson 1992)

from United States, marriage break up was associated with increased daily cigarette consumption relative to staying married. Greater social support from spouses or partners (Waldron and Lye 1989) and the development of more concern with health behaviours are the two suggested reasons for the positive impacts of marriage or partnership (Backett and Davison 1995) on changing smoking status. These may disappear after marriage or partnership dissolution and increased stress, thereby leading to heavier daily consumption of cigarettes and continuity or relapse of smoking.

There were significant sex differences in the relationship between parental transitions and quitting smoking. Having a first child born since baseline was significantly associated with an increased likelihood to quit smoking relative to remaining childless among young women, while no significant association was found among young men. This finding contributes to the limited research on the association between transition into parenthood and smoking cessation among men. This result is perhaps not surprising given the well documented health consequences of maternal smoking to babies and women themselves (U.S. Department of 
1 the likelihood of making a quit attempt was greater among young women than men when

2 moving into parenthood (Tucker et al. 2005). Given the detrimental effects of exposure of

3 children to any parental smoking on vascular health (Gall et al. 2014) and lung function

4 (David et al. 2005), there seems to be a need for more emphasis on the harmful effects of

5 paternal smoking as well.

6 Few studies have examined the relationship between the transition into motherhood and

7 smoking cessation in young women (Cengelli et al. 2012) and the existing evidence has been

8 conflicting (Chen et al. 2001; McDermott et al. 2009; McDermott et al. 2004; Tucker et al.

9 2002) but mainly suggests a positive association. The exception is certain groups, such as

10 single (Siahpush et al. 2013) or younger mothers (Graham et al. 2006; Tucker et al. 2002)

11 where there appears to be less of a protective effect potentially due to the greater burden of social disadvantage. Women may choose to quit smoking during and after pregnancy primarily because of concerns about the baby's health, thus providing a special window of opportunity to promote smoking cessation. A review has demonstrated the efficacy of behavioural interventions assisting pregnant smokers to quit (Patnode et al. 2015). However, in our study this protective effect was absent among women who had additional children born during follow-up. This interesting finding was consistent with previous research that showed smoking cessation during and after pregnancy was inversely associated with parity, with multiparous women quitting smoking less frequently than primiparous women (Lu et al. 2001). One possible explanation is that women who have an experience of smoking during a previous pregnancy and giving birth to a healthy baby are less motivated to quit smoking in subsequent pregnancies (Giglia et al. 2006). It is also possible that women having additional children are more resistant to quitting smoking as a result of higher nicotine dependence and they may represent a group who were unable to quit after their first child was born. If they cannot quit smoking during their first pregnancy, it is less likely to happen in future 
1 pregnancies. This hypothesis was partly supported by our further analyses. We found that

2 women having additional children were more likely to be daily smokers at baseline than those

3 having a first child during follow-up (77.5\% versus $56.6 \%, \mathrm{p}=0.006)$.

$4 \quad$ The public health implications of these findings lie in the opportunities highlighted for

5 future research to inform tobacco control initiatives and public health campaigns. Younger

6 smokers must remain a focus of our tobacco control efforts as the majority (60\%) of current

7 smokers in this study continued their habit over time. There was also a low (11\%) relapse to

8 smoking reiterating that long-term cessation can be achieved. More broadly, our findings

9 support a growing body of literature demonstrating the importance of young adulthood in the

10 adoption and maintenance of health behaviours over the life course (Pampel et al. 2014). The

findings suggest that strengthening the messages regarding the importance and beneficial influences of partners' smoking behaviour, implementing strategies to help non-smoking partners to support their partners to quit and discourage uptake, and calling for more emphasis on multiparous smokers and young male smokers who transit into parenthood in maternity care and paediatric setting. In addition, to facilitate the reinforcement of this procedure, more research is needed to understand, perhaps with qualitative data, the factors underpinning these pronounced shifts in smoking.

Several limitations should be acknowledged in the interpretation of our results. An approximately one-third of participants at baseline were lost to follow-up. Comparison between the follow-up group and those lost to follow-up on some socio-demographic characteristics revealed that non-respondents were more often males, less educated, less employed as professionals or managers, less often married or living as married and less likely to have children at baseline. This may lead to an underestimation of smoking prevalence and some of the associations. Applying inverse probability weighting using weights derived from complete variables in childhood or adulthood to account for these differences produced 
1 similar results, suggesting this is not a major source of bias. The resulting sample size was

2 small, which may have limited power for some comparisons. We used self-reported smoking

3 status, albeit through validated questionnaire at baseline and follow-up. The latest meta-

4 analysis including 67 studies showed a trend of underestimation when comparing self-

5 reported smoking status with smoking status determined through measures of cotinine in

6 biological fluids (Connor Gorber et al. 2009). Smoking trajectories during follow-up were

7 unclear in that some participants may have quit and resumed smoking repeatedly. Success in

8 prolonged smoking abstinence ( $\geq 6$ months) tends to be low at only $3-5 \%$ after a given quit

9 attempt (Hughes et al. 2004), therefore, it is likely that we had some misclassification of point

10 prevalent and continuous abstainers. There were trajectories other than quitting or relapse that

11 are of interest, particularly initiation of smoking. However, only eight people initiated smoking during follow-up so no meaningful analyses of this group could be done. People who had more than one child born during follow-up were categorised into the group of having first child born since baseline, which would underestimate the benefits of the initial transition into parenthood on smoking cessation. The cohort included young adults at baseline some of whom transitioned into middle adulthood by follow-up. As such we were unable to capture the differential effects of life stage transitions, particularly parenthood, in early adulthood that others have demonstrated (Graham et al. 2006). Finally, although our study was longitudinal with measures taken at two time points we examined exposures and outcomes over the same period, which make it difficult to disentangle causality.

Strengths of this study include its longitudinal design and ability to explore the effects among young men and women separately. Furthermore, the mean age of our participants is very similar with the age people normally make partnering and parenting transitions.

In summary, transitions into relationships with a partner and parenthood are associated with beneficial changes in smoking behaviour, but they influence young men and women 
1 differently. The benefits of entering partnered relationships were greater among men than

2 women, and the transition into parenthood was of greater benefit to women than men. 


\section{Compliance with ethical standards}

2 Ethical approval: All procedures performed in studies involving human participants were in 3 accordance with the ethical standards of the institutional and/or national research committee 4 and with the 1964 Helsinki declaration and its later amendments or comparable ethical 5 standards. 


\section{References}

Aiken LS, West SG, Reno RR (1991) Multiple regression: Testing and interpreting interactions. Sage, Thousand Oaks

Australian Bureau of Statistics (2013) Marriages and divorces, Australia, 2013. Australian Bureau of Statistics

http://www.abs.gov.au/ausstats/abs@.nsf/Latestproducts/3310.0Main\%20Features112013 ?opendocument\&tabname=Summary\&prodno $=3310.0 \&$ issue $=2013 \&$ num $=\& v i e w=$. Accessed 1 July 2016.

Australian Institute of Health and Welfare (2014) National Drug Strategy Household Survey detailed report: 2013. Australian Institute of Health and Welfare http://www.aihw.gov.au/publication-detail/?id=60129549469. Accessed 1 July 2016.

Australian Institute of Health and Welfare (2015) Australia's mothers and babies 2013-in brief. Australian Institute of Health and Welfare http://www.abs.gov.au/ausstats/abs@.nsf/Latestproducts/3301.0Main\%20Features32013? opendocument\&tabname $=S u m m a r y \&$ prodno $=3301.0 \&$ issue $=2013 \&$ num $=\& v i e w=$. Accessed 1 July 2016.

Backett KC, Davison C (1995) Lifecourse and lifestyle: the social and cultural location of health behaviours. Soc Sci Med 40:629-638

Banks E, Joshy G, Weber MF et al. (2015) Tobacco smoking and all-cause mortality in a large Australian cohort study: findings from a mature epidemic with current low smoking prevalence. BMC medicine 13:38 doi:10.1186/s12916-015-0281-z

Cengelli S, O'Loughlin J, Lauzon B, Cornuz J (2012) A systematic review of longitudinal populationbased studies on the predictors of smoking cessation in adolescent and young adult smokers. Tob Control 21:355-362 doi:10.1136/tc.2011.044149

Chen PH, White HR, Pandina RJ (2001) Predictors of smoking cessation from adolescence into young adulthood. Addict Behav 26:517-529

Connor Gorber S, Schofield-Hurwitz S, Hardt J, Levasseur G, Tremblay M (2009) The accuracy of selfreported smoking: a systematic review of the relationship between self-reported and cotinine-assessed smoking status. Nicotine Tob Res 11:12-24 doi:10.1093/ntr/ntn010

David GL, Koh WP, Lee HP, Yu MC, London SJ (2005) Childhood exposure to environmental tobacco smoke and chronic respiratory symptoms in non-smoking adults: the Singapore Chinese Health Study. Thorax 60:1052-1058 doi:10.1136/thx.2005.042960

Diemert LM, Bondy SJ, Brown KS, Manske S (2013) Young adult smoking cessation: predictors of quit attempts and abstinence. Am J Public Health 103:449-453 doi:10.2105/AJPH.2012.300878

Eng PM, Kawachi I, Fitzmaurice G, Rimm EB (2005) Effects of marital transitions on changes in dietary and other health behaviours in US male health professionals. J Epidemiol Community Health 59:56-62 doi:59/1/56 [pii]10.1136/jech.2004.020073

Gall S, Huynh QL, Magnussen CG et al. (2014) Exposure to parental smoking in childhood or adolescence is associated with increased carotid intima-media thickness in young adults: evidence from the Cardiovascular Risk in Young Finns study and the Childhood Determinants of Adult Health Study. Eur Heart J 35:2484-2491 doi:10.1093/eurheartj/ehu049

Gall SL, Jose K, Smith K, Dwyer T, Venn A (2009) The Childhood Determinants of Adult Health Study: a profile of a cohort study to examine the childhood influences on adult cardiovascular health. Australas epidemiol 16:35

Giglia RC, Binns CW, Alfonso HS (2006) Which women stop smoking during pregnancy and the effect on breastfeeding duration. BMC Public Health 6:195 doi:10.1186/1471-2458-6-195

Gill SC, Butterworth P, Rodgers B, Mackinnon A (2007) Validity of the mental health component scale of the 12-item Short-Form Health Survey (MCS-12) as measure of common mental disorders in the general population. Psychiatry Res 152:63-71 
Graham H, Francis B, Inskip HM, Harman J, Team SWSS (2006) Socioeconomic lifecourse influences on women's smoking status in early adulthood. J Epidemiol Community Health 60:228-233 doi:10.1136/jech.2005.039784

Henderson S, Duncan-Jones P, McAuley H, Ritchie K (1978) The patient's primary group. Br J Psychiatry 132:74-86

Hughes JR, Keely J, Naud S (2004) Shape of the relapse curve and long-term abstinence among untreated smokers. Addiction 99:29-38

Lee S, Cho E, Grodstein F, Kawachi I, Hu FB, Colditz GA (2005) Effects of marital transitions on changes in dietary and other health behaviours in US women. Int J Epidemiol 34:69-78 doi:10.1093/ije/dyh258dyh258 [pii]

Lu Y, Tong S, Oldenburg B (2001) Determinants of smoking and cessation during and after pregnancy. Health Promot Int 16:355-365

Manchon Walsh P, Carrillo P, Flores G, Masuet C, Morchon S, Ramon JM (2007) Effects of partner smoking status and gender on long term abstinence rates of patients receiving smoking cessation treatment. Addict Behav 32:128-136 doi:10.1016/j.addbeh.2006.03.027

McDermott L, Dobson A, Owen N (2009) Determinants of continuity and change over 10 years in young women's smoking. Addiction 104:478-487 doi:10.1111/j.13600443.2008.02452.xADD2452 [pii]

McDermott L, Dobson A, Russell A (2004) Changes in smoking behaviour among young women over life stage transitions. Aust N Z J Public Health 28:330-335

Mendel JR, Berg CJ, Windle RC, Windle M (2012) Predicting young adulthood smoking among adolescent smokers and nonsmokers. Am J Health Behav 36:542-554 doi:10.5993/AJHB.36.4.11

Pampel FC, Mollborn S, Lawrence EM (2014) Life course transitions in early adulthood and SES disparities in tobacco use. Social science research 43:45-59 doi:10.1016/j.ssresearch.2013.08.005

Patnode CD, Henderson JT, Thompson JH, Senger CA, Fortmann SP, Whitlock EP (2015) Behavioral Counseling and Pharmacotherapy Interventions for Tobacco Cessation in Adults, Including Pregnant Women: A Review of Reviews for the US Preventive Services Task Force. Ann Intern Med 163:608-621

Raymore LA, Barber BL, Eccles JS (2001) Leaving home, attending college, partnership and parenthood: The role of life transition events in leisure pattern stability from adolescence to young adulthood. J Youth Adolesc 30:197-223

Shapiro A, Keyes CLM (2008) Marital status and social well-being: are the married always better off? Soc Indic Res 88:329-346

Siahpush M, Shaikh RA, Tibbits M, Huang TT, Singh GK (2013) The association of lone-motherhood with smoking cessation and relapse: prospective results from an Australian national study. Int J Environ Res Public Health 10:2906-2919 doi:10.3390/ijerph10072906

Tucker JS, Ellickson PL, Klein DJ (2002) Smoking cessation during the transition from adolescence to young adulthood. Nicotine Tob Res 4:321-332 doi:10.1080/14622200210142698

Tucker JS, Ellickson PL, Orlando M, Klein DJ (2005) Predictors of attempted quitting and cessation among young adult smokers. Prev Med 41:554-561 doi:10.1016/j.ypmed.2004.12.002

U.S. Department of Health and Human Services (2012) Preventing Tobacco Use Among Youth and Young Adults: A Report of the Surgeon General. Department of Health and Human Services, Centers for Disease Control and Prevention, National Center for Chronic Disease Prevention and Health Promotion, Office on Smoking and Health http://www.surgeongeneral.gov/library/reports/preventing-youth-tobacco-use/index.html. Accessed 1 July 2016.

U.S. Department of Health and Human Services (2014) The health consequences of smoking -50 years of progress. A report of the Surgeon General. U.S. Department of Health and Human Services, Centers for Disease Control and Prevention, National Center for Chronic Disease 
Prevention and Health Promotion http://www.surgeongeneral.gov/library/reports/50-yearsof-progress/. Accessed 1 July 2016.

Umberson D (1987) Family status and health behaviors: Social control as a dimension of social integration. J Health Soc Behav 28:306-319

Umberson D (1992) Gender, marital status and the social control of health behavior. Soc Sci Med 34:907-917

Umberson D, Chen MD, House JS, Hopkins K, Slaten E (1996) The effect of social relationships on psychological well-being: Are men and women really so different? Am Sociol Rev:837-857

Vangeli E, Stapleton J, Smit ES, Borland R, West R (2011) Predictors of attempts to stop smoking and their success in adult general population samples: a systematic review. Addiction 106:21102121 doi:10.1111/j.1360-0443.2011.03565.x 
1 Table 1 Socio-demographic and health characteristics of participants in the Childhood

2 Determinants of Adult Health Study, Australia, 2004-2006

\begin{tabular}{|c|c|c|c|}
\hline Characteristic & $\begin{array}{c}\text { Total } \\
(\mathrm{n}=\mathbf{1 , 0 8 4})\end{array}$ & $\begin{array}{c}\text { Former smokers } \\
(n=514)\end{array}$ & $\begin{array}{c}\text { Current smokers } \\
(\mathrm{n}=570)\end{array}$ \\
\hline Age (years), Mean (SD) & $31.8(2.7)$ & $32.0(2.6)$ & $31.6(2.7)$ \\
\hline Male, \% (n) & $40.4(438)$ & 33.6 (173) & $46.5(265)$ \\
\hline BMI $\left(\mathrm{kg} / \mathrm{m}^{2}\right)$, Mean (SD) ${ }^{*}$ & $25.2(4.8)$ & $25.1(4.8)$ & $25.2(4.8)$ \\
\hline \multicolumn{4}{|l|}{ Education, \% (n) } \\
\hline Any university education & $30.0(325)$ & $35.8(184)$ & $24.7(141)$ \\
\hline Vocational training & $32.9(357)$ & $33.3(171)$ & $32.6(186)$ \\
\hline High school only & $37.1(402)$ & $30.9(159)$ & $42.6(243)$ \\
\hline \multicolumn{4}{|l|}{ Occupation $^{*}$} \\
\hline Professional or manager & $46.3(393)$ & $50.1(198)$ & $43.0(195)$ \\
\hline Non-manual & $21.9(186)$ & $22.0(87)$ & $21.8(99)$ \\
\hline Manual & $18.0(153)$ & $12.9(51)$ & $22.5(102)$ \\
\hline Not in the workforce & $13.8(117)$ & $14.9(59)$ & $12.8(58)$ \\
\hline \multicolumn{4}{|l|}{ Marital status, \% (n) } \\
\hline Single & $27.8(301)$ & $19.1(98)$ & $35.6(203)$ \\
\hline Married/living as married & $68.3(740)$ & $78.8(405)$ & $58.8(335)$ \\
\hline Separated/divorced/Widowed & $4.0(43)$ & $2.1(11)$ & $5.6(32)$ \\
\hline No children, \% (n) & $46.1(500)$ & $39.3(202)$ & $52.3(298)$ \\
\hline Social support index, Mean (SD) ${ }^{*}$ & $44.9(4.0)$ & $45.1(3.9)$ & $44.7(4.1)$ \\
\hline \multicolumn{4}{|l|}{ Place of residence, $\%(\mathrm{n})^{*}$} \\
\hline Major city & $72.0(779)$ & 75.4 (387) & $68.9(392)$ \\
\hline Regional/rural/remote area & $28.0(303)$ & $24.6(126)$ & $31.1(177)$ \\
\hline \multicolumn{4}{|l|}{ Psychological distress, $\%(\mathrm{n})^{*}$} \\
\hline Low & $89.1(950)$ & $89.9(455)$ & $88.4(495)$ \\
\hline High & $10.9(116)$ & $10.1(51)$ & $11.6(65)$ \\
\hline \multicolumn{4}{|l|}{ Childhood self-rated health, \% (n) } \\
\hline Very good/good & 34.4 (293) & 34.5 (144) & 34.1 (149) \\
\hline Average & $45.0(384)$ & $44.1(184)$ & $45.9(200)$ \\
\hline Poor/very poor & $20.6(176)$ & $21.3(89)$ & $20.0(87)$ \\
\hline
\end{tabular}

3 SD, standard deviation; BMI: body mass index.

$4 \quad{ }^{*}$ Sample size ranged from 849 to 1082. 
Table 2 Relative risk (95\% CI) of quitting smoking relative to continuing smoking, and resuming smoking relative to remaining quit, by partnering transitions, the Childhood Determinants of Adult Health Study, Australia, 2004-2011*

\begin{tabular}{|c|c|c|c|c|c|}
\hline \multirow{2}{*}{ Partnering transitions } & \multirow{2}{*}{$\begin{array}{l}\text { Number (\%) } \\
\text { with outcome }\end{array}$} & \multicolumn{2}{|c|}{ Unadjusted } & \multicolumn{2}{|c|}{ Adjusted $^{*}$} \\
\hline & & $\mathbf{R R}$ & $95 \% \mathrm{CI}$ & $\mathbf{R R}$ & $95 \%$ CI \\
\hline \multicolumn{6}{|c|}{ Current smokers at baseline - males $(n=265)$} \\
\hline Not partnered both times & $12 / 59(20.3)$ & Ref. & & Ref. & \\
\hline Became partnered & $31 / 55(56.4)$ & 2.77 & $1.59,4.83$ & 2.84 & $1.62,4.98$ \\
\hline Stayed partnered both times & 59/141 (41.8) & 2.06 & $1.20,3.53$ & 2.12 & $1.18,3.80$ \\
\hline Became separated/divorced/widowed & $2 / 10(20.0)$ & 0.98 & $0.26,3.75$ & 1.01 & $0.26,3.96$ \\
\hline \multicolumn{6}{|c|}{ Current smokers at baseline - females $(n=305)$} \\
\hline Not partnered both times & 26/65 (40.0) & Ref. & & Ref. & \\
\hline Became partnered & $32 / 56(57.1)$ & 1.43 & $0.98,2.08$ & 1.50 & $1.03,2.18$ \\
\hline Stayed partnered both times & 64/161 (39.8) & 0.99 & $0.70,1.41^{\dagger}$ & 1.13 & $0.80,1.62$ \\
\hline Became separated/divorced/widowed & 7/23 (30.4) & 0.76 & $0.38,1.51$ & 0.83 & $0.42,1.62$ \\
\hline \multicolumn{6}{|l|}{ Former smokers at baseline $(n=514)$} \\
\hline Not partnered both times & $11 / 49(22.5)$ & Ref. & & Ref. & \\
\hline Became partnered & 2/60 (3.3) & 0.15 & $0.03,0.64$ & 0.14 & $0.03,0.58$ \\
\hline Stayed partnered both times & 40/381 (10.5) & 0.47 & $0.26,0.85$ & 0.51 & $0.27,0.95$ \\
\hline Became separated/divorced/widowed & $5 / 24(20.8)$ & 0.93 & $0.36,2.37$ & 0.95 & $0.38,2.40$ \\
\hline
\end{tabular}

3 Values in bold denote statistically significant results.

$4 \quad$ RR, relative risk; CI, confidence interval.

$5 \quad$ *Adjusted for baseline age, sex (only in resuming smoking analyses), education, parenting transitions and follow-up length.

6 † Statistically significant difference compared with people who became partnered. 
Table 3 Relative risk (95\% CI) of quitting smoking relative to continuing smoking, and resuming smoking relative to remaining quit, by parenting transitions, the Childhood Determinants of Adult Health Study, Australia, 2004-2011*

\begin{tabular}{|c|c|c|c|c|c|}
\hline \multirow{2}{*}{ Parenting transitions } & \multirow{2}{*}{$\begin{array}{l}\text { Number (\%) } \\
\text { with outcome }\end{array}$} & \multicolumn{2}{|c|}{ Unadjusted } & \multicolumn{2}{|c|}{ Adjusted $^{*}$} \\
\hline & & $\mathbf{R R}$ & 95\% CI & $\mathbf{R R}$ & 95\% CI \\
\hline \multicolumn{6}{|l|}{ Current smokers at baseline - males $(n=265)$} \\
\hline No children both times & 36/98 (36.7) & Ref. & & Ref. & \\
\hline First child born since baseline & 23/52 (44.2) & 1.20 & $0.81,1.80$ & 1.05 & $0.68,1.62$ \\
\hline Additional children born since baseline & 20/50 (40.0) & 1.09 & $0.71,1.67$ & 0.97 & $0.58,1.60$ \\
\hline Same number of children both times & 25/65 (38.5) & 1.05 & $0.70,1.57$ & 0.96 & $0.60,1.53$ \\
\hline \multicolumn{6}{|c|}{ Current smokers at baseline - females $(n=305)$} \\
\hline No children both times & 46/103 (44.7) & Ref. & & Ref. & \\
\hline First child born since baseline & $33 / 44(75.0)$ & 1.68 & $1.28,2.21^{\dagger}$ & 1.74 & $1.30,2.33^{\dagger}$ \\
\hline Additional children born since baseline & $14 / 48(29.2)$ & 0.65 & $0.40,1.07$ & 0.68 & $0.41,1.13$ \\
\hline Same number of children both times & $36 / 110(32.7)$ & 0.73 & $0.52,1.03$ & 0.76 & $0.53,1.09$ \\
\hline \multicolumn{6}{|l|}{ Former smokers at baseline $(n=514)$} \\
\hline No children both times & 15/104 (14.4) & Ref. & & Ref. & \\
\hline First child born since baseline & 10/98 (10.2) & 0.71 & $0.33,1.50$ & 0.68 & $0.31,1.49$ \\
\hline Additional children born since baseline & $17 / 141(12.1)$ & 0.84 & $0.44,1.60$ & 1.00 & $0.47,2.11$ \\
\hline Same number of children both times & $16 / 171(9.4)$ & 0.65 & $0.33,1.26$ & 0.82 & $0.38,1.78$ \\
\hline
\end{tabular}

3 Values in bold denote statistically significant results.

$4 \quad$ RR, relative risk; CI, confidence interval.

$5 *$ Adjusted for baseline age, sex (only in resuming smoking analyses), education, partnering transitions and follow-up length.

6 Statistically significant difference compared with people who had additional children born since baseline and people who had the same of number of

7 children. 


\section{Figure legends}

2 Figure 1 Flow chart of recruitment and retention of participants for Childhood Determinants

3 of Adult Health (CDAH) study, Australia, 1985-2011. 